\title{
Trazando el origen de la fotografía en 2 dimensiones y 3 dimensiones a través de las representaciones de animales
}

\section{Tracing the origin of photography from two dimensions to three dimensions through animal representations}

\author{
AUTORA: \\ Ana María Guerra \\ Doctoranda en Filosofía por la Universidad Autónoma de Barcelona \\ Artista visual
}

Resumen

Este artículo es un estudio sobre la evolución de la fotografía de 2 dimensiones a 3 dimensiones a través de la representación de animales. El objetivo es trazar el origen de las imágenes generadas por ordenador (CGI) desde una mirada crítica hacia el impacto del hombre en otras especies y la concepción de la realidad.

Palabras clave

Fotografía, animales, evolución, dioramas, CGI, 3D, realidad virtual, realidad, ficción, hiperrealidad.

\section{Abstract}

This paper examines the evolution of photography from two dimensions to three dimensions through animal representations. The objective is to trace the origin of Computer Generated Images (CGI) from a critical view of the impact humans have had on other species and the definition of reality.

Key words

Photography, animals, evolution, dioramas, CGI, 3D, virtual reality, reality, fiction, hyperreality. 


\section{Introducción}

Esta investigación es un intento de trazar los orígenes de la fotografía en 2 dimensiones y 3 dimensiones para entender el presente de las imágenes generadas por ordenador (CGI). Las representaciones de animales son un factor clave para entender la evolución del medio fotográfico y el poder de la imagen para moldear nuestra percepción de la realidad.

El primer capítulo explora el nacimiento de la fotografía en la época victoriana donde el colonialismo y el capitalismo basado en el progreso tecnológico sentaron las bases del mundo actual. Los animales han estado presentes en la historia de la fotografía desde los primeros días, capturar su movimiento fue un reto que aceleró la evolución del medio. La fotografía se ganó rápidamente las etiquetas de objetividad y veracidad porque se creía que el hombre intervenía muy poco en el proceso mecánico de capturar la realidad. Los científicos se aprovecharon de la objetividad intrínseca asignada a la cámara para transmitir sus teorías.

El segundo capítulo analiza los dioramas de Carl Akeley para el Museo de Historia Natural de Nueva York bajo las teorías de Donna Haraway y las fotografías de los mismos dioramas que sacó Hiroshi Sugimoto aplicando los conceptos de hiperrealidad y simulacro de Jean Baudrillard.

El tercer capítulo examina la obra Post Natural History del artista Vincent Fournier sobre su colección de animales ficticia creada íntegramente con un CAD software. Conceptos de virtualidad de Baudrillard y teorías del libro Mil Mesetas de Deleuze y Guattari son aplicados para entender la evolución del medio fotográfico.

\section{1 . Los primeros días de la fotografía en 2 dimensiones}

La Reina Victoria era una ávida propulsora de la fotografía y el progreso tecnológico, estableciendo los estándares del mundo en el que vivimos hoy. Su entusiasmo por el nuevo medio y su amor por los animales, la convirtieron en la monarca de la fotografía y los perros. Para 1850 en Europa, una clase media emergente tenía acceso por primera vez a productos que antes sólo estaban al alcance de la aristocracia. Los retratos fotográficos y los perros de compañía permitieron a la burguesía emular el estilo de vida de la nobleza. El fenómeno fotográfico cautivó al mundo, llenando un vacío social (Merritt y Barth, 2002, p. 22-25).

Los animales han sido retratados desde la misma creación de la fotografía en el siglo XIX. EI daguerrotipo de Jacob Byerly tomado en 1848, que muestra a un niño con su perro, es una de las primeras imágenes de animales registradas en la historia. Louis Daguerre anunció la invención del daguerrotipo sólo nueve años antes. Las restricciones técnicas del nuevo medio exigían la completa inmovilidad de los sujetos durante largos tiempos de exposición, lo que complicaba enormemente retratar animales, por este motivo la imagen muestra al niño enfocado pero la cara del perro borrosa. 


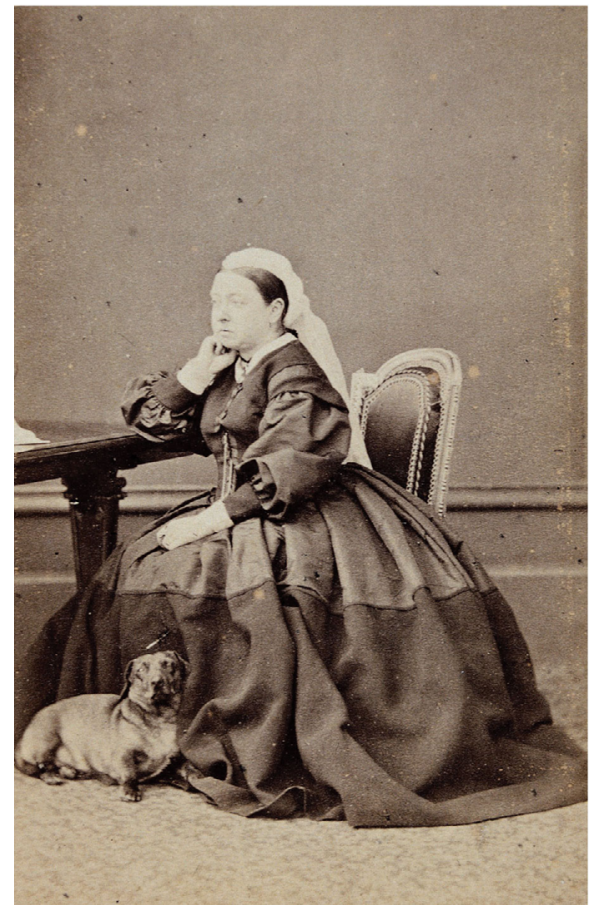

Figura 1: Hills \& Saunders, 'Her Majesty the Queen', 1870.

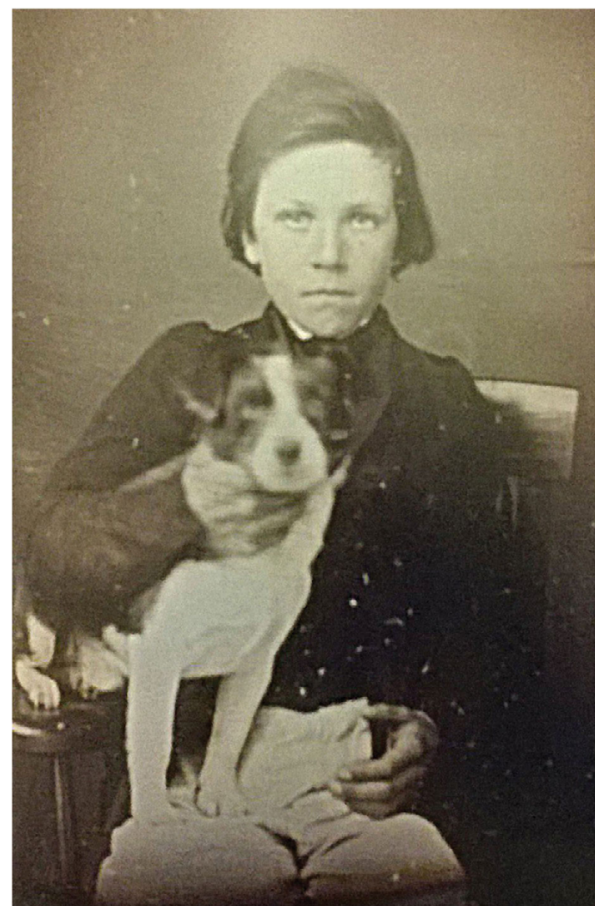

Figura 2: Jacob Byerly, ‘Unknown', 1848.

Los científicos también estaban fascinados con el nuevo invento. Al principio, las fotografías se juzgaron según su semejanza con la realidad, de la misma manera que los dibujos y las huellas dactilares. Desde la década de 1830 hasta la de 1880, los tiempos de exposición se acortaron desde minutos hasta fracciones de segundo lo que hizo que la fotografía conquistara la etiqueta de veracidad. En la época victoriana, la fotografía instantánea se definió como un proceso natural, donde las imágenes se creaban a sí mismas a través de la exposición a la luz. Se creía que había poco espacio para la mediación humana en este proceso mecánico. Los científicos comenzaron a usar fotografías para ilustrar sus teorías, debido a la objetividad implícita asignada a la cámara. Charles Darwin se convirtió en uno de los primeros científicos en usar fotografías para publicaciones científicas. En su libro La expresión de las emociones en el hombre y en los animales (1871), usó fotografías para representar las emociones humanas pero debido a las restricciones del medio tuvo que usar ilustraciones para representar las expresiones de los animales (Prodger, 2009).

Las limitaciones percibidas en la fotografía para capturar el movimiento fue la fuerza motriz de muchos de los avances tecnológicos en cámaras fotográficas. La locomoción de los animales fue una inspiración para desarrollar nuevas tecnologías que permitieran congelar la realidad animada de la naturaleza.

Eadweard Muybridge fue el primer fotógrafo que capturó con éxito el movimiento de los ani- 
males. El caballo en movimiento fue un proyecto patrocinado por Leland Stanford, el fundador de la Universidad de Stanford. Él contrató a Muybridge porque quería entender cómo se movían las patas de sus caballos de carrera al trotar. Stanford quería hacer una apuesta proponiendo que en algún momento cuando los caballos corren, tienen las cuatro patas en el aire. Muybridge y un equipo de ingenieros construyó una pista y un banco de doce cámaras en el almacén de Stanford, en Palo Alto. Instalaron cables de disparo que los caballos activaban a cada paso que daban, capturando el movimiento de las 4 patas de los animales. En 1884, Muybridge probó la teoría de Stanford, usando la fotografía de alta velocidad, capturó el vuelo del caballo usando la técnica del stop-motion (Prodger, 2003).

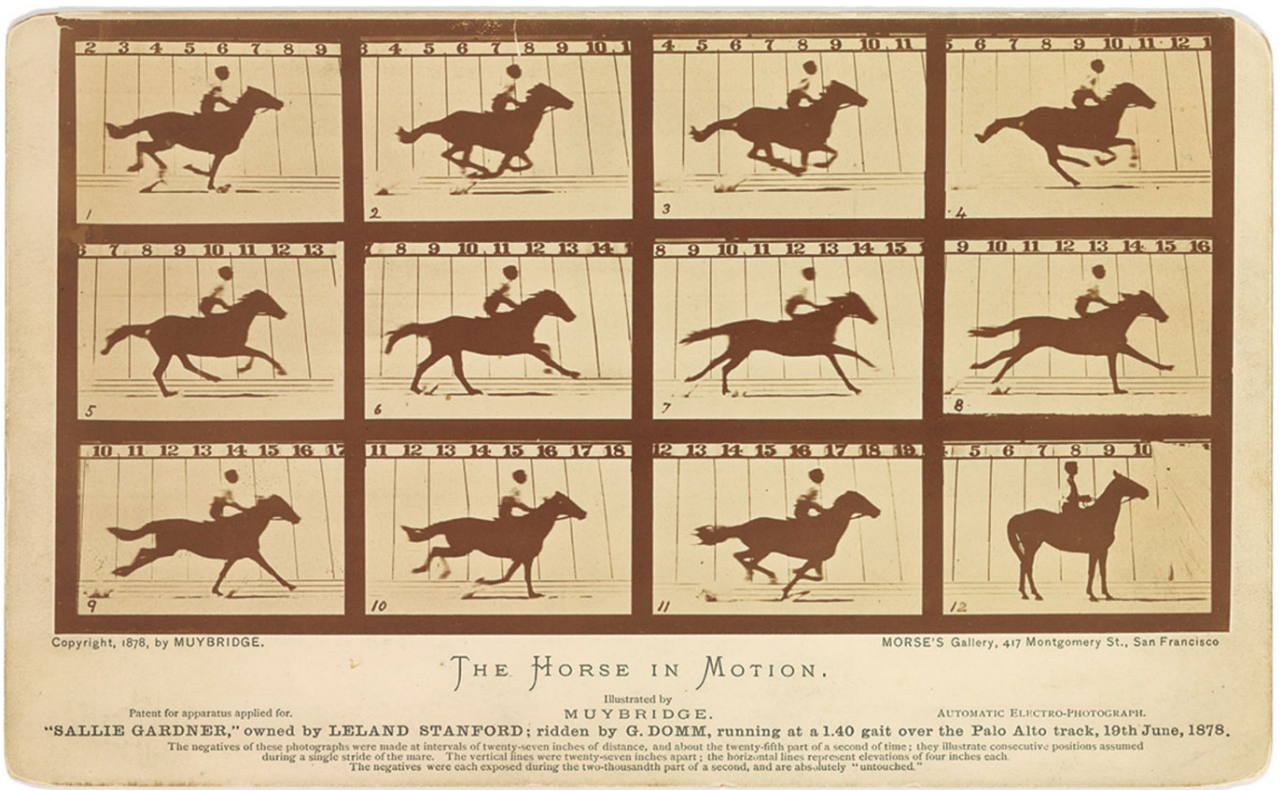

Figura 3: Eadweard Muybridge, 'Horse in motion', 1878.

Antes de la notable realización de Muybridge, varios fotógrafos utilizaron taxidermia para crear falsas fotografías instantáneas de animales. John Dillwyn Lewelyn experimentó con pájaros disecados haciéndolos parecer como si estuvieran atrapados en movimiento. Al colocar pájaros en ambientes exteriores conseguía imágenes convincentes. Otros fotógrafos como Léon Crémiere no obtuvieron un resultado tan realista. La Figura 5 muestra lo que son claramente perros disecados en un paisaje urbano. La edad de oro de la taxidermia fue durante el período victoriano, cuando tener un animal disecado en casa como decoración era símbolo de un alto status social, era una representación simbólica de la conquista de tierras lejanas y exóticas. El desarrollo de la fotografía se produjo con la revolución industrial, ligada a los avances en la química y la expansión colonial impulsada por la economía capitalista. 


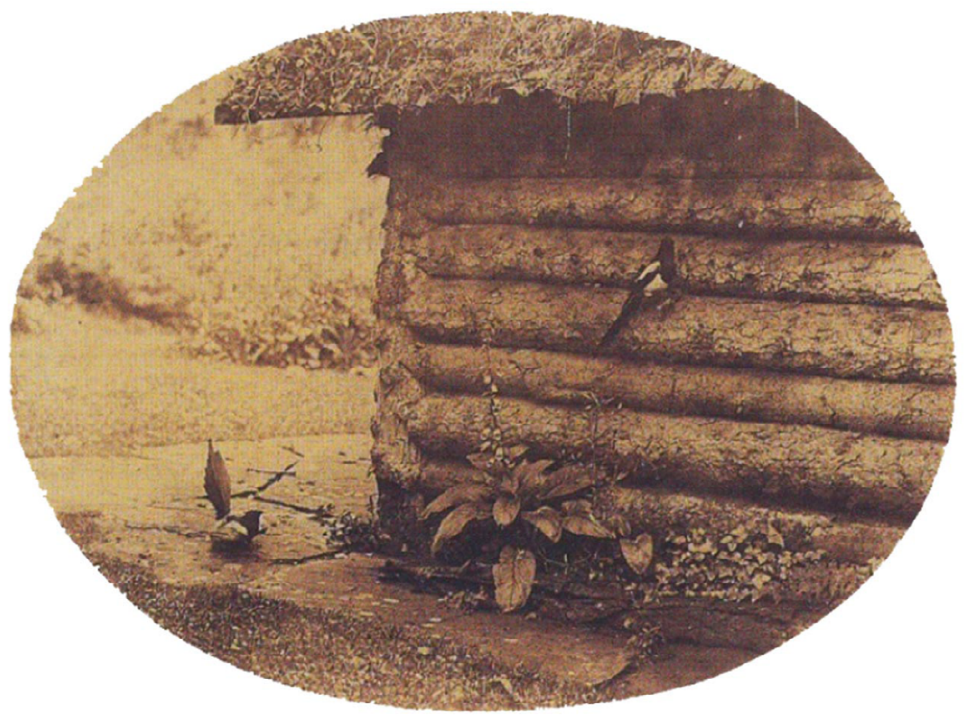

Figura 4: John Dillwyn Lewelyn, 'Two birds at a rustic Cottage', 1852

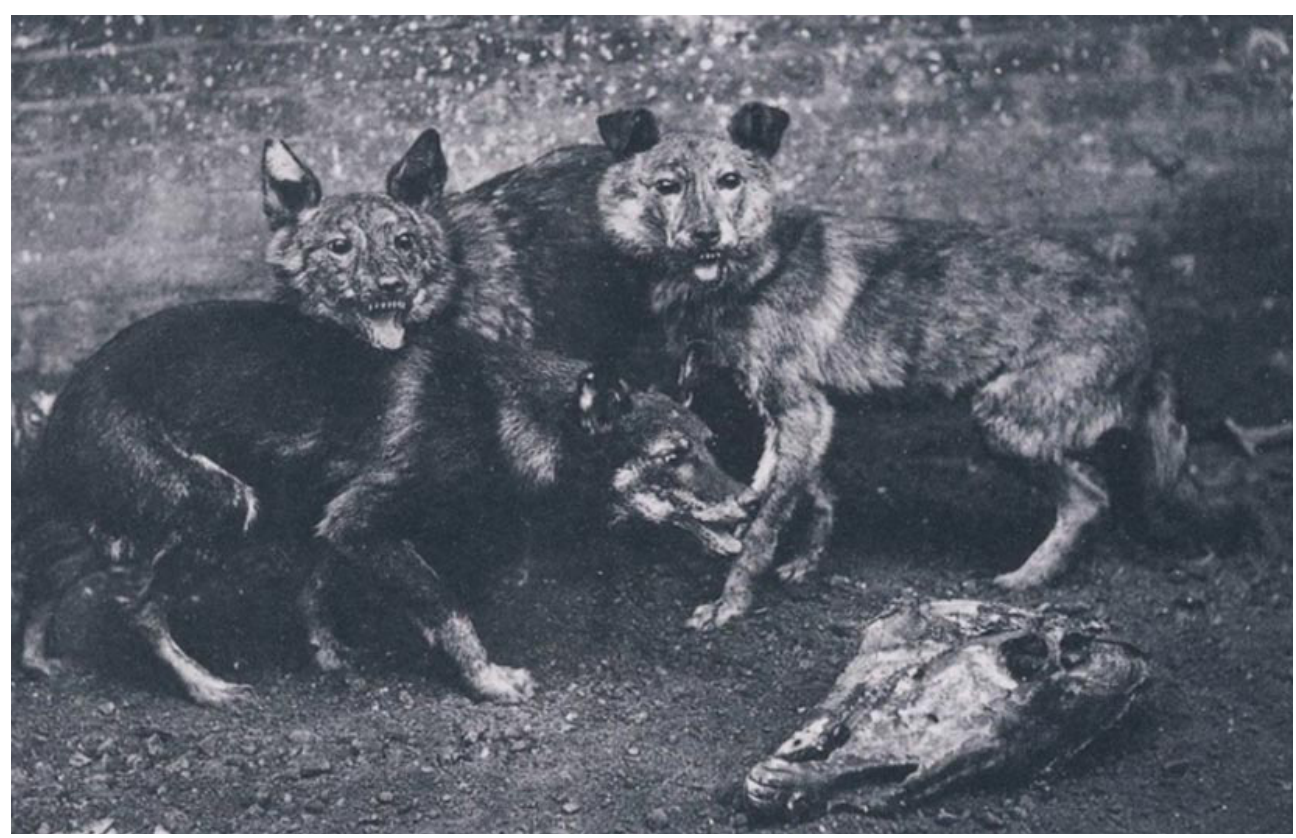

Figura 5: Leon Crémiere, 'Savage Expressions of a Dog and a She-Wolf', 1863 


\section{Dioramas, la primera forma de realidad virtual}

La fotografía de gelatina de plata se estableció como la representación fiel de la realidad en el mundo bidimensional. Por otro lado, los dioramas fueron los primeros objetos que proporcionaron una experiencia visual tridimensional para el público. La palabra 'diorama', derivada del griego dia (a través de) y horama (ver), fue acuñado por Louis-Jacques-Mandé Daguerre, un pionero en fotografía y un talentoso escenógrafo. Daguerre patentó el diorama en 1822 para describir una nueva forma teatral de arte visual. Daguerre mejoró la técnica pintando a los 2 lados de grandes piezas de tela translúcida consiguiendo que las imágenes se transformaran dramáticamente cuando fueran iluminadas por delante y por detrás. El efecto fue un desafío perceptivo para los espectadores en ese momento. La ilusión de profundidad era tan efectiva que estaban convencidos de que las representaciones eran maquetas a gran escala con objetos reales.

La irrupción de la fotografía a mediados del siglo XIX provocó una disminución en la popularidad de los dioramas, que prácticamente desaparecieron hasta la década de 1920, cuando fueron revividos como material educativo. El éxito de los dioramas en el ámbito científico se dio por 3 factores principales: la creciente degradación de hábitats naturales, el conservacionismo y la introducción de la taxidermia en el diseño de escenarios para exposiciones (Quinn, 2006).

\subsection{El gigante de Karisimbi de Akeley}

Los dioramas de museos tienen sus manifestaciones más conocidas en la obra del taxidermista, fotógrafo y biólogo Carl Akeley para el Museo Americano de Historia Natural de Nueva York. La sala de Akeley está formada por 28 dioramas que representan las principales zonas geográficas de África y sus grandes mamíferos. Los grupos están formados por un macho dominante, que en la mayor parte de casos fue inmortalizado en un eterno gesto de vigilia, una o dos hembras y un bebé. En algunos casos, hay ejemplares jóvenes vigorosos, en su mayoría machos, pero nunca encontraremos especímenes viejos o imperfectos. Los estándares de Akeley exigían las muestras más hermosas de cada especie.

El diorama The Giant of Karisimbi fue para Akeley su creación más importante ya que los gorilas eran su animal favorito por su parecido a los humanos. El taxidermista se embarcó en una expedición al Congo para la realización de dicha pieza. La imagen de abajo muestra al gigante de Karisimbi que fue cazado por Herbert Bradley a la derecha, Mary Hasting Bradley a la izquierda, y Akeley en el medio sosteniendo la mandíbula del gorila. Mujeres blancas fueron invitadas al viaje porque Akeley quería mostrar que incluso una mujer podría matar a un gorila. Su intención era debilitar las connotaciones heroicas de la caza en un intento por preservar la especie africana: "Como naturalista interesado en preservar la naturaleza me alegraba hacer cualquier cosa que pudiera hacer menos atractiva la matanza de animales" (Akeley 1923, p. 203). 


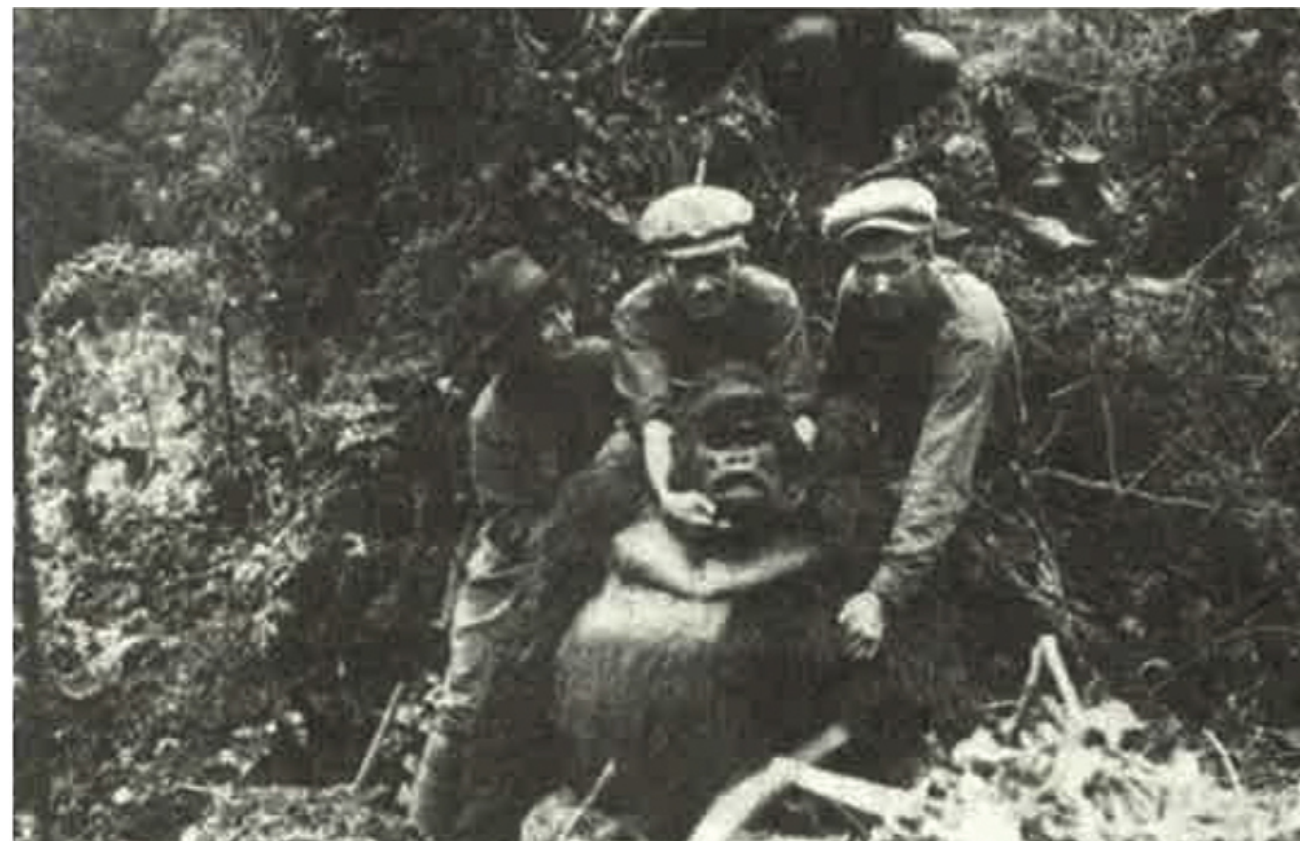

Figura 6: The Giant of Karisimbi with Akeley, Marie and Herbert Bradley, 1921.

Akeley seleccionó este espécimen como protagonista de su diorama porque era el macho más hermoso. Lo describió como una magnífica criatura con el rostro de un amable gigante que no haría ningún daño excepto quizás en defensa propia o en defensa de su familia (Akeley 1923, p. 230). A pesar de esta afectuosa descripción, el diorama muestra un macho dominante con un papel protagonista, mientras que en el plano secundario, se encuentra el resto del grupo que parece estar subyugado a él. 


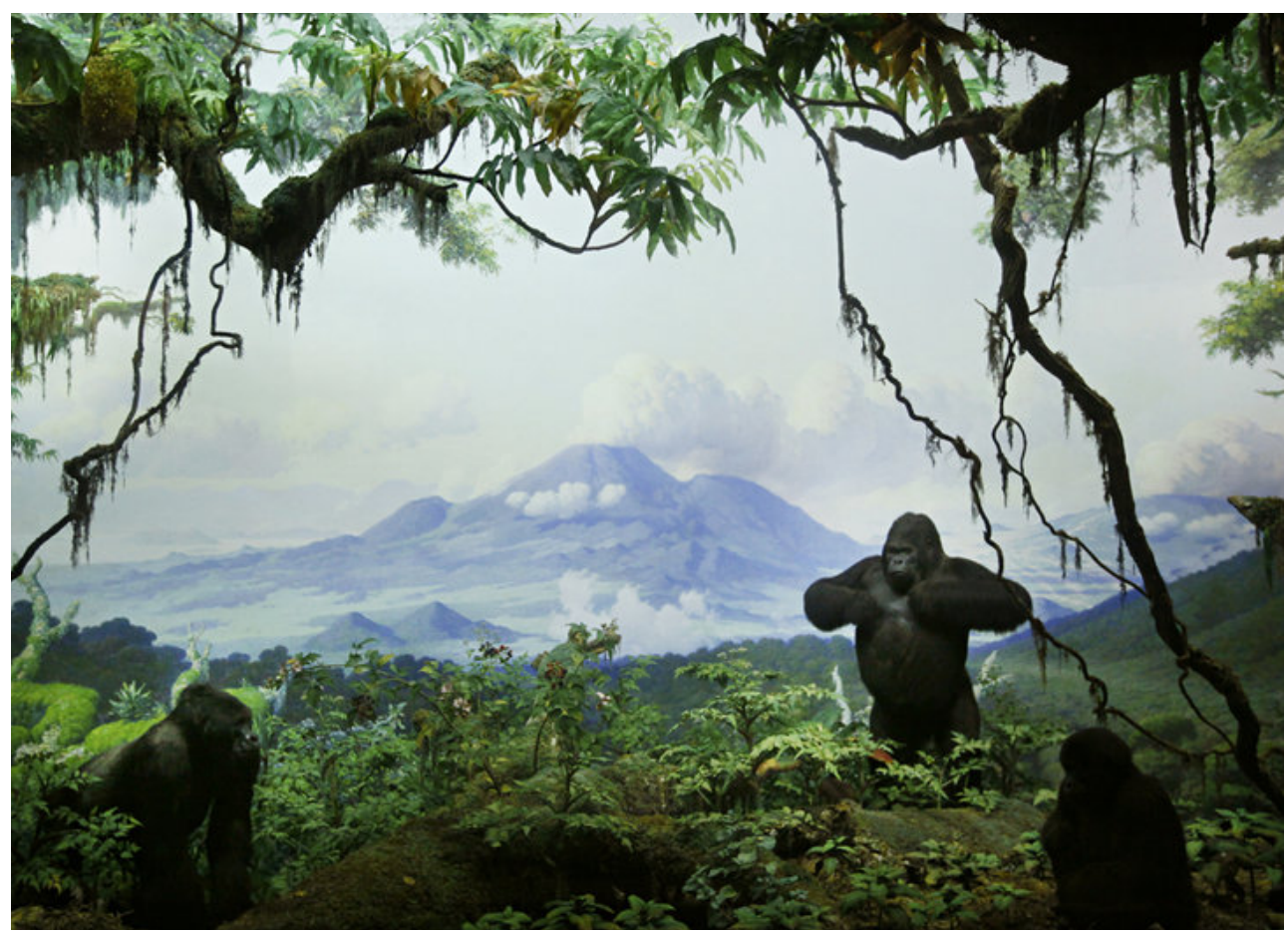

Figura 7: The Giant Karisimbi's Dlorama, American Museum of Natural History, 2006.

Donna Haraway analiza los dioramas de Akeley en su libro El patriarcado del osito Teddy. Sobre ellos afirma que dicen tanto de la sociedad que los creó como de los mundos que representan. Para Haraway las pintorescas representaciones familiares de los animales y sus jerarquías reflejan las concepciones de raza, género y clase social durante la presidencia de Teddy Roosevelt. Los dioramas eran la respuesta a la irrupción del socialismo, el feminismo y el aumento del número de la población inmigrante que amenazaba el dominio de la mayoría norteamericana caucásica. Para Haraway, habían tres propósitos principales para recrear los hábitats de los animales africanos: exhibir el poder de los hombres exploradores occidentales, la eugenesia, y la conservación de especies (Haraway, 2004).

Según Haraway, la realidad y la ficción han sido fabricados de la misma materia prima; ambos son el resultado de la intervención humana y se han desarrollado siguiendo demandas subjetivas. La diferencia es que la realidad se refiere al presente y la ficción se refiere al futuro: "Etymologically, facts refer to performance, action, deeds done-feats, in short. A fact is a past participle, a thing done, over, fixed, shown, performed, accomplished. Facts have made the deadline for getting into the next edition of the paper. Fiction, etymologically, is very close but differs by part-of-speech and tense. Like facts, fiction refers to action, but fiction is about the act of fashioning, forming, inventing, as well as feigning or feinting" $(2012$, p. 19).

Para Haraway, el vínculo entre la realidad como el resultado final y la ficción como el trabajo en los procesos que pueden dirigir nuestras acciones futuras, podría llevarnos a identificar como los mecanismos científicos modelan nuestras percepciones. 


\subsection{Los dioramas de Sugimoto, hiperrealidad y simulacro}

Dioramas de Hiroshi Sugimoto son representaciones de representaciones. Sugimoto empezó a tomar fotografías de los dioramas de Akeley en 1972 y continúa capturándolas hasta hoy en día, es un trabajo en progreso. Según el fotógrafo, lo que le fascinan de estas formas de realidad virtual es que representan la vida y la muerte simultáneamente. Declaró que su vida como artista comenzó cuando se dio cuenta de que podía devolver la vida a los animales de Akeley con sus imágenes. El realismo de sus fotografías en blanco y negro se debe a la riqueza de su técnica. El artista emplea una cámara de gran formato para capturar sus sujetos y mezcla su propio revelador usando una receta tradicional. Sugimoto es un alquimista moderno, su objetivo es representar la historia natural como una falsa imagen con la ilusión del realismo. Al hacer esto, plantea el uso problemático de la palabra realismo en este contexto, y va más allá al cuestionar lo que es la realidad: "Aunque si nadie ve a través de una imagen falsa, tal vez es la realidad que es la falsedad después de todo" (Sugimoto, 2014).



Figura 8 Hiroshi Sugimoto, 'Gorilla' from Dioramas 1994.

La fotografía de Sugimoto parece más real que el diorama de Akeley, aunque la recreación del hábitat sea una visión subjetiva de quienes intervinieron de una u otra forma en su creación. Es el ejemplo perfecto de lo que Jean Baudrillard denominó hiperrealismo. El autor usa una fábula de Jorge Luis Borges para definir lo que es la hiperrealidad. La historia trata de un Imperio que creó un mapa a escala 1:1, es decir del verdadero tamaño del territorio que representaba. Las siguientes generaciones no apreciaron el arte de la cartografía tanto como sus antepasados, así que no protegieron el mapa contra las inclemencias del tiempo. El mapa comenzó a desin- 
tegrarse con el paso del tiempo. La fábula concluye diciendo que todavía hay ruinas del mapa en el desierto, habitado por animales y mendigos. Baudrillard sostiene que esta historia ha expirado para nosotros y se ha convertido exactamente en lo contrario, para el autor la hiperrealidad ha reemplazado a la realidad: "Hoy la abstracción ya no es la del mapa, la del doble, la del espejo o la del concepto. Simulación ya no es el territorio, es la generación por modelos de un real sin origen ni realidad, un hiperrealismo. El territorio ya no precede al mapa, ni sobrevive a él. Es sin embargo el mapa que precede al territorio -precesión de simulacros- el que engendra el territorio, y si hay que volver a la fábula, hoy es el territorio cuyo trozos se pudren lentamente a través de la extensión del mapa. Es lo real, y no el mapa, cuyos vestigios persisten aquí y allá en los desiertos que ya no son los del Imperio, sino los nuestros. El desierto de lo real en sí mismo." (Baudrillard, 1994, p. 9)

El diorama The Giant of Karisimbi de Akeley y la fotografía de Hiroshi Sugimoto del mismo, nos hacen pensar como las representaciones humanas de otras especies son subjetivas y en este sentido cabe cuestionarnos qué es la realidad. Mientras miles de especies de animales desaparecen por todas partes, sus representaciones se han multiplicado infinitamente en imágenes, dioramas, películas, zoológicos; todas estas son representaciones de los originales.

Según Guy Debord el capitalismo cambió la percepción porque todo se ha convertido en una representación. Los animales ya no pertenecen a la realidad, viven en la hiperrealidad. Han desaparecido a través de la sociedad del espectáculo (Debord, 2010, p, 37-101).

\section{Post Natural History de Vincent Fournier y la virtualidad}

Con la llegada de las imágenes generadas por ordenador (CGI) ha nacido la fotografía virtual. No es necesario tener un referente del mundo real para crear un espacio con un CAD software; todo puede venir de nuestra imaginación y ser fotografiado con una cámara virtual.

En cuanto a la virtualidad, Baudrillard afirmó que es la fase del "asesinato del signo". Él siempre cuestionó la arbitrariedad de la lingüística y la existencia de la realidad. El signo definido por Saussure está formado por el significante, significado y referente. 'El significante' se refiere a la palabra, 'el significado' se refiere al concepto, y 'el referente' se refiere al mundo real. La virtualidad es el proceso en el que todo el universo de significados pierde sus referentes. A modo de ejemplo, menciona las cuevas de Lascaux en Francia, que son famosas por sus animales paleolíticos. Las cuevas originales han estado cerradas durante muchos años, y es el simulacro, Lascaux 2, que los visitantes hacen cola. La mayoría de ellos ya ni siquiera saben que es un simulacro. Ya no hay ninguna indicación del original en ningún lugar. Es una especie de prefiguración del mundo que nos espera: una copia perfecta, que ni siquiera sabremos que es una copia (Baudrillard, 2004, P. 52).

Sobre el futuro, Baudrillard mostró su lado más optimista, afirmando que el advenimiento del CGI puede conferir a la sociedad una "ironía objetiva" que nos haga ser cada vez más incrédulos de todo lo que vemos, lo que, de alguna manera, podría traernos una nueva libertad (Smith, 2010).

El proyecto de Vincent Fournier, Post Natural History (2012), muestra una colección fictícia de imágenes de animales generadas íntegramente con un CAD software. Fournier colaboró 
con un equipo de especialistas en genética evolutiva para imaginar cómo pueden evolucionar algunas especies, adaptándose al entorno cambiante del futuro. El proyecto es una mezcla de realidad y ciencia ficción. Para el artista es importante que sus historias sean basadas en conocimiento científico para que puedan ser potencialmente ciertas. La imagen de la derecha Moon Jellyfish, es descrita como una especie que puede viajar entre dimensiones. La imagen de la derecha muestra Ethereal Jellyfish, cuya singularidad es que transmite datos desde las profundidades oceánicas.
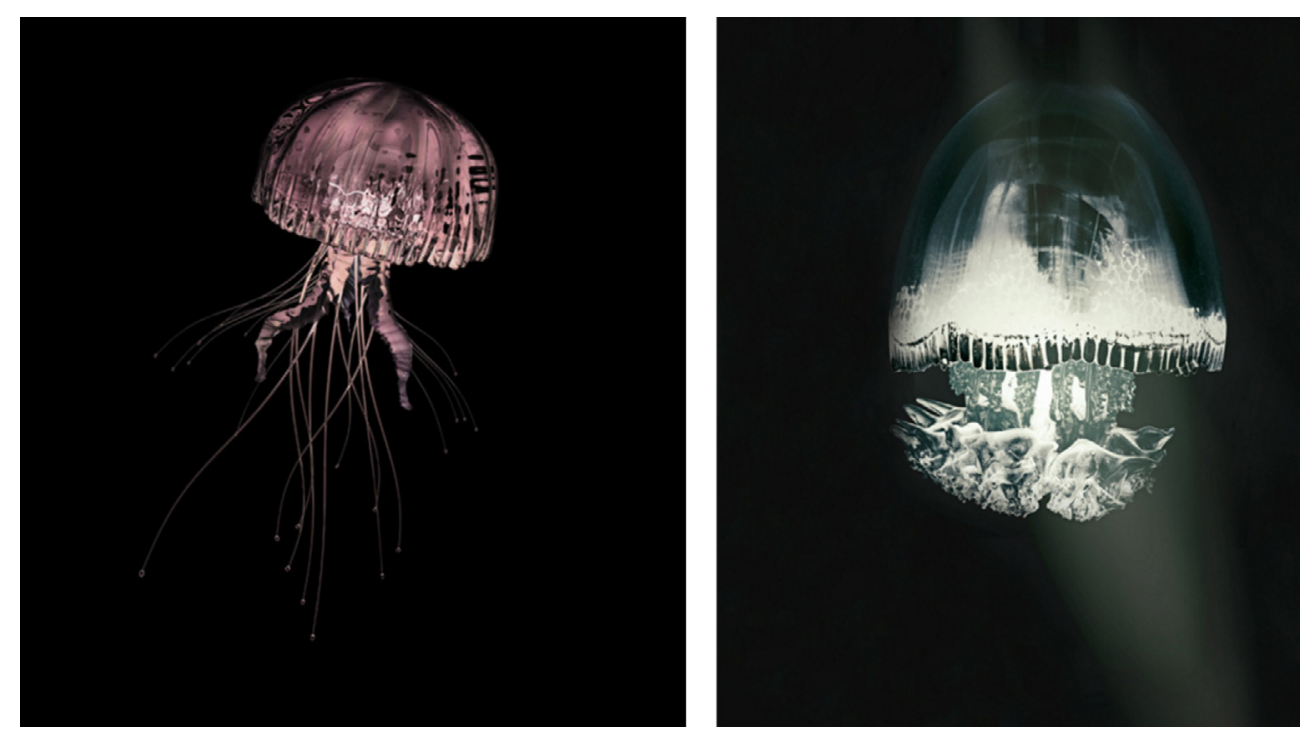

Figura 9. Vincent Fournier, 'Ethereal Jellyfish', 2012.

Figura 10. Vincent Fournier, 'Moon Jellyfish', 2012.

En 2012, el mismo año en que Fournier presentó su exposición, la marina de los Estados Unidos anunció el desarrollo de una medusa robótica apodada 'Robojelly', que fue diseñada con fines de vigilancia, control de aviones no tripulados y operaciones de rescate (Ubergizmo, 2012). En este sentido podemos otorgar al arte el poder de anticiparse a lo que va a pasar. Analizar la tecnología desde una perspectiva histórica nos puede permitir predecir que vendrá en el futuro. Los avances tecnológicos suelen ser el resultado de intereses políticos y económicos. 



Figura 11. 'Robojelly', designed to work as a search rescue and surveillance for the U.S. Navy, 2012.

Sobre el CGI podemos decir que su antecesor fueron los dioramas. El diseño de entornos virtuales, requiere de un proceso de texturizado denominado 'UV maps' algo similar al trabajo de un taxidermista. Para hacer los mapas de texturas UV, los diseñadores deben desmontar los objetos modelados para convertirlos en 2 dimensiones. En este sentido, los espacios virtuales podrían considerarse dioramas digitales.

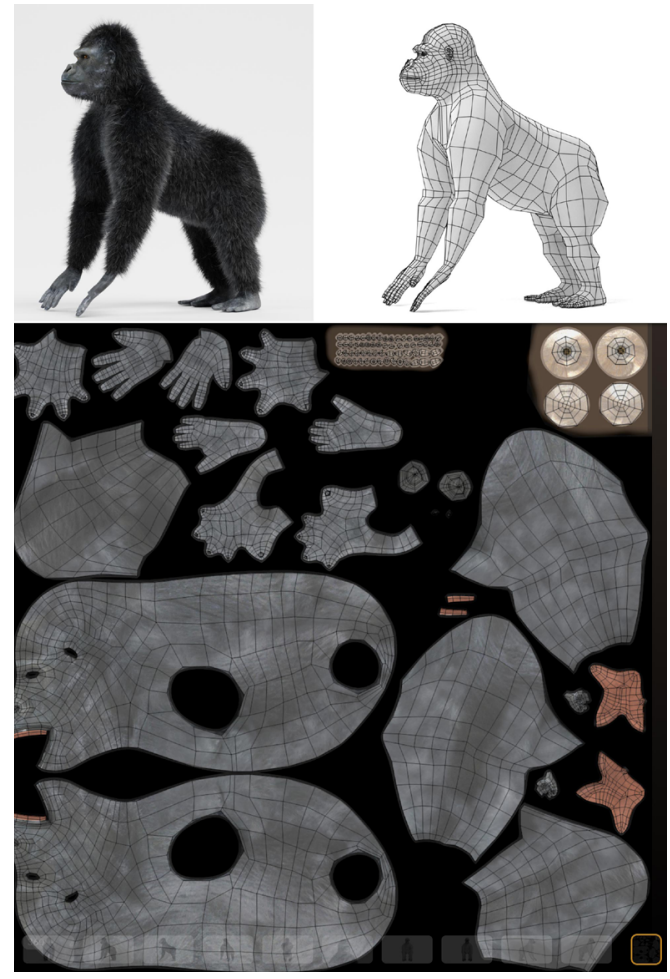

Figura 12.

Bescec, UV map 'Gorilla', Turbosquid.Go 
Según Deleuze y Guattari, la repetición existe en todos los estados del tiempo. En el pasado, la repetición se produce a través de la memoria, en el presente se produce a través de hábitos y costumbres, y en el futuro la repetición toma la forma de un eterno retorno. En el futuro, la repetición tendrá que liberarse de la memoria y de los hábitos que son la única manera de lograr transformación creativa ( 2002, p. 171).

El concepto de eterno retorno es tomado de Nietzsche por Deleuze y Guattari pero con un giro diferente. En lugar de concebir el futuro como la evolución hacia el super hombre, ellos reformularon el eterno retorno, tomando la creatividad como fuerza motriz para cambiar el sistema. La transformación creativa se basa más en la simbiosis que en la mutación. Por eso Deleuze y Guattari llamaron a este proceso involución porque no se relaciona con evolucionar en una sola dirección; el rizoma crece en muchas direcciones. (Paro, 2010)

Vemos como en la historia de la fotografía, la tecnología ha ido evolucionado, repitiendo los mismos principios pero de una forma más sofisticada. Lo que queda claro es que el desarrollo tecnológico evoluciona en detrimento de los hábitats naturales con trágicas consecuencias como la extinción de miles de especies provocadas por el impacto del hombre en el planeta.

El mayor interés de Deleuze en la biología es el concepto de multiplicidades. En Devenir animal, Deleuze y Guattari se inspiraron en la capacidad de insectos como las hormigas para realizar tareas complejas sin ningún tipo de control centralizado. La organización de dichas comunidades no son simplemente una unidad homogénea, se diferencian continuamente, y esta diferenciación interna puede ser entendida como el motor de su creatividad. Las multiplicidades mantienen a los seres individuales dentro de la comunidad. La diferenciación es clave en el proceso de transformación creativa. (Paro, 2010)

Desde el arte se debe cuestionar qué es la realidad para los humanos y que es la realidad para otras especies. El psicólogo cuantitativo Don Hoffman (After On, 2019), quien ha pasado las últimas décadas perfeccionando una teoría extraordinaria sobre la naturaleza de la realidad sostiene que la visión humana es limitada en comparación a otras especies de animales como los pájaros o las abejas por ejemplo que pueden percibir una mayor amplitud del espectro magnético. Es tiempo de mirar a las otras especies con quienes cohabitamos desde otra perspectiva, valorar la biodiversidad del planeta y ser crítico con las aparentes verdades que nos rodean.

\section{Conclusión}

El estudio de las nuevas tecnologías como el CGI desde una perspectiva histórica nos puede ayudar a entender cómo ha evolucionado el medio fotográfico. El progreso tecnológico que occidente abrazó desde la revolución industrial ha tenido un gran impacto en la degradación del planeta por lo que analizar la propagación de imágenes de animales en contraste con su desaparición del mundo físico es oportuna para cambiar de perspectiva, lo que Deleuze y Guattari llaman involucionar en vez de evolucionar. Determinar el poder que tienen las imágenes para moldear lo que consideramos realidad nos puede ayudar a romper con sesgos cognitivos como la hiperrealidad y el simulacro.

Desde el principio, las representaciones de animales en 2 dimensiones y 3 dimensiones han sido utilizadas para manipular la sociedad a través de diferentes formas: educación, espectácu- 
lo o propaganda. Las imagénes ejercen un control omnisciente de la sociedad. Han facilitado un proceso de homogeneización global que hace que la resistencia creativa sea más difícil. Los consumidores de todo el mundo tienen la misma imaginación colectiva; la realidad sensorial se compone de las mismas imágenes. No se trata de preguntarse si las tecnologías pasadas o las tecnologías presentes son mejores, el verdadero conflicto es el poder que tienen las imágenes para cegarnos. Los entornos virtuales podrían convertirse en plataformas alternativas para ser críticos y expresarnos de forma creativa o podría ser un anzuelo seductor, para escapar virtualmente de las problemas del mundo físico.

Mirar a los animales desde el arte puede ser la clave para descubrir nuevas realidades. Es tiempo de observar a otras especies con quienes cohabitamos desde nuevas perspectivas, valorar la biodiversidad del planeta y ser críticos con las aparentes verdades que nos rodean.

\section{Ilustraciones}

\section{Figura 1}

Hills \& Saunders, 'Her Majesty the Queen', 1870.

Fuente: Hills \& Saunders, 'Her Majesty the Queen', In Merrit, M. Barth, M. (2008) A Thousand Dogs. Köln: Taschen.

\section{Figura 2}

Jacob Byerly, 'Unknown', 1848.

Fuente: Jacob Byerly, 'Unknown', 1848. In Merrit, M. Barth, M. (2008) A Thousand

Dogs. Köln: Taschen.

\section{Figura 3}

Eadweard Muybridge, 'Horse in motion', 1878.

Fuente: Eadweard Muybridge, 'Horse in motion', 1878. In Prodger, P. (2003) Time Stands Still. Oxford: Oxford University Press.

\section{Figura 4}

John Dillwyn Lewelyn, 'Two birds at a rustic Cottage',1852

Fuente: John Dillwyn Lewelyn, 'Two birds at a rustic Cottage',1852. In Prodger, P. (2003) Time Stands Still. Oxford: Oxford University Press.

\section{Figura 5}

Leon Crémiere, 'Savage Expressions of a Dog and a She-Wolf', 1863

Fuente: Leon Crémiere, 'Savage Expressions of a Dog and a She-Wolf',1863. In

Prodger, P. (2003) Time Stands Still. Oxford: Oxford University Press.

\section{Figura 6}

The Giant of Karisimbi with Akeley, Marie and Herbert Bradley, 1921.

Fuente: The Giant of Karisimbi with Akeley, Marie and Herbert Bradley, 1921. In

Haraway, D. (2015) El patriarcado del osito Teddy. Barcelona: Printcolor

\section{Figura 7}

The Giant Karisimbi's Dlorama, American Museum of Natural History, 2006.

Fuente: The Giant Karisimbi's Diorama, American Museum of Natural History, 2006.

Haraway, D. (2015) El patriarcado del osito Teddy. Barcelona: Printcolor.

\section{Figura 8}

Hiroshi Sugimoto, 'Gorilla' from Dioramas 1994.

Fuente: Hiroshi Sugimoto, 'Gorilla' from Dioramas 1994. In Sugimoto, H. (2014) Hiroshi

Sugimoto: dioramas. Bologna: Damiani. 


\section{Figura 9}

Vincent Fournier, 'Ethereal Jellyfish', 2012.

Fuente: Vincent Fournier, right 'Moon Jellyfish.' Left 'Ethereal Jellyfish' En http:// www.vincentfournier.co.uk (Consultado 14.03.16)

\section{Figura 10}

Vincent Fournier, 'Moon Jellyfish', 2012

Fuente: Vincent Fournier, right 'Moon Jellyfish'. Left 'Ethereal Jellyfish' En http://

www.vincentfournier.co.uk (Consultado 14.03.16)

\section{Figura 11}

'Robojelly', designed to work as a search rescue and surveillance for the U.S. Navy, 2012.

Fuente: 'Robojelly!' En: http://www.popsci.com/technology/article/2012-03/hydro

gen-powered-robojelly-pulses-through-water-conduct-surveillance

(Consultado: 04.04.16)

\section{Figura 12}

Fuente: Bescec, UV map 'Gorilla', Turbosquid. En: https://www.turbosquid.com/es/3d-models/ western-gorilla-model-1239073 (Consultado: 17.11.19)

\section{Bibliografía}

- $\quad$ Akeley, C. (1923) In the Brightest Africa. New York: Douleday, Page \& Co.

- After On Podcast. (2019). Episode 53: Don Hoffman, The Case Against Reality. Disponible en: https://after-on.com/episodes-31-60/053 [Consultado 10 Oct. 2019].

- $\quad$ Baker, S. (2000) The Postmodern Animal. London: Reaktion Books.

- $\quad$ Baudrillard, J. (1994) Simulacra and Simulation. Ann Arbor: University of Michigan Press.

- Baudrillard, J. (2004) The Intelligence of Evil or the Lucidity Pact. Oxford:Berg.

- $\quad$ Baudrillard, J. (1996) The Perfect Crime. New York: New Left Books.

- Berger, J. (2007) Why Look at Animals? in Kalof and Fitzgerald (ed.) The animals reader. Oxford:Berg.

- Burt, J. (2007) The illumination of the Animal Kingdom in Kalof and Fitzgerald (ed.) The animals reader. Oxford: Berg.

- Darwin, C. (1872) The Expression of the Emotions in Man and Animals. London: Fontana.

- Darwin, C. (1859) The Origin of Species. Oxford: Wordsworth Editions.

- Deleuze, G. (2002) Diferencia y Repetición. Buenos Aires: Amorrortu.

- Deleuze, G. (2015) Mil mesetas. Valencia: Pre-textos.

- Debord, G. (2012) La sociedad del espectáculo. Valencia: Gallimard.

- $\quad$ Fontcuberta, J. (2014) Pandora's camera. London: Mack.

- Fontcuberta, J. (1999) Fauna. Madrid: Photovision.

- Haraway, D. (2007) Cyborgs to Companion Species in Kalof and Fitzgerald (ed.) The animals reader. Oxford: Berg.

- Haraway, D. (2004) The Haraway Reader. New York: Routledge.

- Haraway, D. (2012) The Companion Species Manifesto. Chicago: Prickly Paradigm Press.

- Haraway, D. (2015) El patriarcado del osito Teddy. Barcelona: Printcolor

- Merrit, M. Barth, M. (2008) A Thousand Dogs. Köln: Taschen.

- Parr, A. (2010) The Deleuze Dictionary Revised Edition. Edinburgh: Edinburgh University Press.

- Parr, A. (2009) Of Rhizomes, Smooth Space, War Machines and New Media in Poster and Savat (ed.) Deleuze and New Technology. Edinburgh: Edinburgh University Press. 
- $\quad$ Prodger, P. (2003) Time Stands Still. Oxford: Oxford University Press.

- Prodger, P. (2009) Darwin's camera. Oxford: Oxford University Press.

- Quinn, S. (2006) Windows on nature : the great habitat dioramas of the American Museum of Natural History. New York: Harry N. Abrams.

- $\quad$ Riordan, K. (2015) Hiroshi Sugimoto and the photography of theater in Performance Research. Routledge: London.

- Rubinstein, D. (2013) The Grin of Schrödinger's Cat: Quantum Photography and the Limits of Representation in Rubinstein, Goldin and Fischer (ed.) On the Verge of Photography. Birmingham: Article Press.

- Rubinstein, D. Golding, J. and Fisher, A. (2013) On the Verge of Photography. Birmingham: Article Press.

- $\quad$ Saussure, F. (1983) Course in General Linguistics. Paris: Editions Payot.

- Smith, R. (2010) The Baudrillard Dictionary. Edinburgh: Edinburgh University Press.

- Steyerl, H. (2012) The wretched of the Screen. Berlin: Strenberg Press.

- Sugimoto, H. (2014) Hiroshi Sugimoto: dioramas. Bologna: Damiani.

- Ubergizmo. (2012). Robojelly is a robot jellyfish [Video]. [online] Available at: http://www. ubergizmo.com/2012/03/robojelly-is-a-robot-jellyfish/ [Accessed 11 Apr. 2016]. Vimeo. com. (2015). Print the Legend. [online] Disponible en: https://vimeo.com/127029314 [COnsultado 9 Abril, 2016].

\section{CURRICULUM VITAE. ANA MARÍA GUERRA.}

Doctoranda en Filosofía por la Universidad Autónoma de Barcelona y artista visual. Mi investigación y mi trabajo se centran en las colaboraciones interdisciplinarias entre arte y ciencia para concienciar a la sociedad sobre el impacto del ser humano en otras especies y en el medio ambiente. Mi formación académica ha sido en la Universidad de las Artes de Londres, donde realicé un máster en fotografía en el año 2016. Mi trabajo se ha expuesto en Inglaterra, China y Estados Unidos; y ha sido publicado en medios especializados en nuevas tendencias en arte contemporáneo. 